\title{
A System of Didactic Games as a Foundation of Teaching History in Secondary School
}

\author{
Nadegda Makarova, Marina Potemkina, Nina Chernova, and Andrey Dorozhkin
}

Nosov Magnitogorsk State Technical University, 455000, Magnitogorsk, Lenin Ave., 38, Russia,

\begin{abstract}
Today, an important part of an education system is use of various didactic tools. Among them a significant role belongs to didactic games that allow realising purposeful development of intellectual skills of children, their interest in studies, as well as formation of creative potential and independent work in teaching history. In the course of analysis of an experience of using didactic games at history lessons, the authors were guided by works of S.A. Ezhov, O.S. Gazman, V.P. Bespalko, R.M. Mironova, P.I. Pidkasistiy, G.K. Selevko et al. The empirical basis of the study included practical classes of teachers of history in Magnitogorsk and their analysis at methodological seminars and round tables. Besides, the authors used guidance papers published earlier. An important source and a legal basis for application of didactic games at school are the Federal State Educational Standard. To achieve the set goal, such methods were applied as: a method of generalizing advanced practices of teachers of history; a study of foreign and domestic scientific works in psychology, pedagogy, devoted to the problems of education, nontraditional forms of teaching lessons, modern pedagogical technologies. At present, in the historical education, role-playing, theatrical and business games have gained the most widespread. Analysis of these games and peculiarities of their use at school among schoolchildren of different age groups has shown that a business game should be used predominantly at high school, while role-playing and theatricalized games have already become applicable in 5-7 grades.
\end{abstract}

Currently, the system of education is considered an important part of societal development. School is allotted a difficult task: educating and teaching children. Among multiple variants to resolve this issue, one shall note a way of efficient development of teaching process, namely, development and application of special teaching methods, assuming a goal-oriented development of children's intellectual skills, their interest in studying, as well as formation of their creative potential and ability for independent work. Thus, secondary schools see implementation and application of modern teaching technologies in the educational process.

Today, almost every teacher of history applies new forms and methods of teaching in their practical work. It is recognized, that it is linked to a renewed style of thinking characteristic of those teachers, who aspire to achieve high-quality solutions of educational and teaching tasks within a given limit of a small number of contact hours. Forms of lesson that ensure activation of each and every pupil, increase the value of knowledge and responsibility of every pupil for the outcome of the lesson are of great importance in school. We hold that these issues may be productively resolved with the help of didactic games. By means of gaming activity, pupils retain historical data better; they experience increased interest in studying history, while the emotional side of the gaming process activates mental processes and functions of pupils. Another advantageous moment in a didactic game is the fact, that it facilitates application of knowledge to a new unfamiliar situation, i.e., the material that was coped with by the pupils is used through a non-conventional practice; it creates variety and enthusiasm in class.

While analyzing experience from application of didactic games in history lessons, we built on previous works of S.A. Yezhov, O. C. Gazman, V.P. Bespalko, R. M. Mironova, P.. I. Pidkasisty, G. K. Selevko and others [1-3], where a methodology for application of gaming technology is revealed. Revealing the nature of the didactic game as a method of teaching history has become the main goal of our research. Factual foundation of the research was formed by practical lessons conducted by history teachers of the city of Magnitogorsk, and analysis of these lessons during methodological seminars and round-table meetings. Besides, the authors used previously published methodological developments. An important source and the legal framework for application of didactic games in secondary school is the Russian Federal State Educational Standard (FSES), which contains the

* Corresponding author makarovanadia@mail.ru 
following passage: «game technology allows organizing group work during the educational process while taking into consideration pupil's individual features of perception and constructing a process of mutual teaching». As per the FSES, communicative and personal universal educational actions are formed [4].

Methodological framework of the study has been formed by common scientific and pedagodical provisions: systematicity, historicity, typology, dialectics, activity and cultural congruence, incessancy of learning in the education system, variability of methods and forms of education, problematical character, interlinkage between the practice and the theory of education, communality of general education and specific training in institutions of general education; play activity theory, concepts of pedagogy and psychology in pupil personality development. To achieve the stated goal the following methods were used: generalization of best practices of history teachers, study of domestic and foreign works in psychology and pedagogy dedicated to problems of education, nontraditional forms of lesson delivery, modern teaching technologies.

Psychology considers game play as one of the main categories of activity, aimed at forming and obtaining social experience. A didactic game, unlike a regular game, is conducted with a predetermined goal, to attain a certain educational result. For many years, playing games served as a method of education and training. Extensive use of games with educational objectives was common for many great practitioners and theoreticians. For F. Frebel, game play was a foundation of education, and his system of games as a whole assumed both physical and moral development. M. Montessori when using didactic games held, that they provide development, independence and cognitive activity. For K. D. Ushinsky, game is a free activity of children, where playing brings something special into development; such form of teaching is undoubtedly interesting, educational, but never entertaining. Considering didactic game, A.P. Usov thinks that different procedures, methods, tasks of gaming type intensify child's perceptivity, brings entertainment into the educational process, as well as variety of learning activities. A concept of didactic game has been studied by multiple scholars [5-10], especially recently. Didactic game takes its place as one of commonly available and trendy forms of training, while the technology itself takes a significant place in work of a teacher who aspire for high results of teaching. The latest developments in didactic games are aimed at finding and implementing the aspects that develop intelligence, initiative and logic of students during the game.

Today, there are well-formed ideas of mutual links between the play and learning in pedagogy; the best structure of the play process has been selected, as well as conditions of the most valuable forms and methods of teacher's leadership in the play activity of their pupils. Game technologies and schooling are directed at developing skills in observation, attention, comparison, concentration, memory, imagination, activity and inquisitiveness. At that, social experience functions are engaged, which are characteristic of every game technology. So, a didactic game is a type of educational activity represented as an educational game with a certain set of conditions and rules, where the main goal is to form knowledge and skills.

A specific feature of didactic game is that it shall have its own foundational structure, which will specifically differ it from other forms of activity. Important elements of the structure are: game concept, game actions and positions, educational content or training tasks, equipment and results of a game. Game concept is the very first component of the game structure; as a rule, it is used in the game's name. The game concept is realized in a certain educational task that shall be solved during the lesson [8]. Often, the concept is represented as a question and it always reinforces the cognitive nature of the play process, requires the players to show specific knowledge obtained during the playing. An important part of a didactic game is formed by game actions, defined from the rules of the game, facilitating cognitive activity of pupils, giving them a chance to show their skills, apply their knowledge, capabilities and mastery in achieving the goal of the game.

The didactic game shall have certain attributes: there shall be a clearly stated training goal and a corresponding training result. They may be justified and shall be characterized with educational and cognitive direction. The didactic game always have a clear result representing the end of the play activity and expressing the finish of the game. It will be, first of all, as a solution of the set didactic task and will allot the pupils with mental and cognitive satisfaction from participation in the gaming process. For a teacher, the result is always a level attained by the pupils in mastery of material and its possible applications. It would be great to conduct a joint analysis of a completed game together with a survey of participants. If there is not enough time, one may, following a method of A.N. Lutoshkin, state their emotional state in a common table, where game participants are giving their assessment of the game in this way.

All the components of the didactic game's structure interact. If even one of them is absent, the game is destroyed. Without the game conception, game actions, without game-organizing arrangements, the didactic game either loses its specific form or becomes a typical performance of exercises and solution of tasks. When preparing to a lesson where the didactic game is to be employed, one shall complete a brief characteristic of the game process: a script. One shall define time limits of the game, take into account the level of knowledge and age peculiarities of the participants, arrange intersubject relationships. Bringing together all the components of the game and their interaction increases the organized nature of the game, its efficiency, leads to a successful result.

Problematics of didactic game is actively studied in the current literature by teachers and psychologists alike. V.A. Sukhomlynsky held that the importance of play in child's development is very high and even that its lack will form a deficient child. Gaming is similar to cinema; 
it gives children a wide range of concepts and knowledge about their environment. When defining the nature of the didactic game, one shall select its most important components. Firstly, activity, perceived as an important function that realizes human life, as well as an active attitude to the world and environment; this is a place where intellectual, emotional and volitional qualities of a person originate, here mental processes, character and abilities are being formed. Secondly, a conventionality, being understood as an attribute of reflection of reality, showing a discrepancy between the image and its original. In this situation, a pretend activity is assumed.

However, not any action in pretend play situation is a game. A regular task in a text book is also simulated: there is a given situation and a question. But there is no game, because the problem statement is not fascinating. For pupils performing the task, playing the game comes first, and learning only second. To make an activity a game, it shall be fascinating for the players. In the game, activity is a means, while the objective is the interest. In teaching work, the conventionality is applied to learning, exercise, development of various skills and competences. It shall be also noted, that the activity shall be unpredictable, otherwise the game becomes inviable. Doubtless, the term of «amusement» is a concrete reflection of the nature of the game, because it directly shows presence of the element of the activity. But this concept implies an element of fascination as well, that is, the amusement in this situation is subjective, and a situation of play may not appear as a game to everybody.

Thus, specifics of a didactic game is in its having two interconnected components: conventionality and activity. Without the conventional component, it becomes just a task, an exercise. For example, a pupil retells the previously covered material. It is a performance of a regular task. If we add conventionality to this task, it will become a game. For example, we may select one more pupil and provide the two of them with conditions: they shall retell to attract a much interest as it is possible, by marking facts that are more important, etc, - thus, a regular task becomes a game.

Thus, the game will be a didactic one, if the content of its conventional component is based upon the educational content, while the activity component is based on a manipulative material [69]. Dual nature of the didactic game manifests in the fact that when engaging with a game, the main thing for the pupils is the game itself, while for the teacher it is the result of the training, which is the main thing.

A spectrum of goal orientations consists of a union of goals of the teacher and those of the pupils, of both teaching and playing objectives. Organizing the didactic game in class, the teacher pursues some specific teaching goals: developing, educational, diagnostic ones. Teaching goals of the didactic game are implemented by the teacher for the pupils directly and indirectly, by turning them into game objectives: complete the task ahead of others, reach the final, become the winner, etc.. The teaching goals direct the pupils to the educational nature of the work; game objectives direct them to attain an efficient result.
During the didactic game, an important and critical activity is undertaken for the pupil's personal development, their obtaining new knowledge and skills. Such important things shall be implemented in the context of the game. For each pupil, attaining the game objectives in the context of approaches and actions of the game shall first of all become a means for attaining serious personal goals - those of education and training. In the opposite case, the game becomes a unidirectional activity, concentrated on winning and self-expression. If the conventional objectives are incomplete, than the pupils staying within the limits of the form of the play, withdraw from it and implement typical educational functions, at that, the form of the play appear as an obstacle in the work. Performing the playing functions, the pupil never leaves the situation of an actual educational process, performing activities, which do not differ from those performed within the framework of certain forms of educational process, being in completely real relationships with other participants of the game.

The game objectives are an ordered component and they are guaranteed by relevant motivations. Various types of motivation find a problematic crossing in an educational game: effective and procedural, personal and group, that of success and educational motivation. Depending on which motivations are of higher priority, a certain type of personality will be formed. Orienting the pupils onto the result alone and not on the process of the educational activity may lead to formation of competitive traits of personality, an urge to become the first no matter what. So, such a motivational foundation of the game shall be created, where educational motivations has a priority.

The pupil, together with various affections, advancing them during the process of the game, attains new ways of educational and cognitive activity through the game. That is why, supervision of educational game shall cover two directions: pupils shall get as much positive emotions during the game as possible: pleasure, enjoyment, delight, that is, one shall not approach the game too pragmatically, but in such a way that keeps children's emotional involvement with the process; it is important, that the game includes a significant resource of "nutrition" for learning and self-development and thus serves as an unconventional channel for interiorization of educational material in accordance with the didactic task set for the pupils.

The content of the educational game is based on the educational process plot and directed towards studying the environment on behalf of the pupils, towards reclaiming educational and training activities through independent methods in accordance with the training material, as well as towards development of a valuebased world view. In other words, the content of educational game is all knowledge, abilities, skills, views, convictions. It should be taken into account, that during the game the pupils often reflect the principles and character of interactions between the elder people. By repeating activities and relationships between the elder people arising in business and social context, children have deeper understanding of the meanings in 
the life of grown-ups, realizing the moral of the human world in which they live.

Didactic games in educational process are divided along multiple criteria and form a wide typology. Games are marked by type of activity, by a direction of teaching process, by a method of playing. Let us consider some types of didactic games in more detail, namely, business games and role-playing games.

There is no clearly-formulated concept of a business game in Russian pedagogy yet. However, let us consider some of the existing concepts for general understanding. A business game is a fragment of pedagogical work, based on didactic criteria: availability and scientific rigor, methodicalness and regularity, demonstrativeness and development of individual and age-specific features. The business game is a study of processes and mechanisms in decision-making. During the business game, decisions are gradually being elaborated, significant factors are checked step-by-step, in-game and newly-obtained information is being analyzed. During the game, the pupils consider and assess a situation, render and discuss decisions, build certain relationships within their collective, such that shall reflect competitive moment, joint work, interactions, etc. The business game reworks the picture of the past in such a way, that the pupil plays exclusively a role of a contemporary person (a historian, a writer, a journalist). Business games arose in XVII century, when so-called 'military chess' where used in officer training; then there were 'military amusements' of young Peter the Great, which later laid ground for business games in the army for soldiers; business games have seen active research interest and development since 1960s. Business games are more actively applied in higher education that in secondary school. However, creative teachers develop business games and successfully apply them in their practical teaching. Business game has the same main features and principles, as general-purpose didactic games; however, it has its own specific features. Business game also has its own approaches and methods of use at the history lessons. The game is conducted following the scenario of real historical events and facts, where their result is already known to everyone involved, or following an own scenario, where the outcome of current events is predicted. As there is no common definition of the nature and method of business game arrangement in literature, so there is no established game structure, however some structural elements in some situations has a general nature. Usually, authors proceed from their common sense and practical experience when designing a game or adopting certain structural components from other authors. A foundation of business game design is formation of gaming and imitation images which are integrally layered as a representation of structure. Business game is type of pupils' activity taking up insignificant amount of time and space, as a subjectoriented activity with direct links to day-to-day reality, achieving the goal to change the self-reflection with respect to this subject. In other words, the business game is directly linked to the foundation of the everyday life of people. At the history lessons, the business game helps solving complex issues by using specific conditions of analysis, motivating creative interest of pupils by means of special methods of work. For example, a game known as «Jeopardy! - The Great Patriotic War» was developed to stimulate children's interest in events of the history of their country. The game consists of several units (at teacher's discretion), which shall be solved by teams (by turns, or for speed, also at teacher's discretion). The units contain tasks of various types and difficulty. This game is best used for consolidation of previously studied material. The business game at a history lesson forms a strong interest in the subject in pupils; thanks to their fascination with the interactive study of the past they obtain skills in both critical study of the past and sympathy with different world views and judgments. An energetic acquaintance with historical information "through self" provides the pupils with more knowledge and facilitates better assimilation and memorization in the present and better application in the future. During the game, the pupils also learn to give analysis of historic events and facts, correlate the events with the necessary historic period, and assess historical figures and cultural monuments. Skills of independent work are formed due to working with documents, encyclopedias, memoirs, regular textbook, etc. The business game at the history lesson remakes the past and the process of the game happens during the past epoch. With the help of such gaming process, the teacher monitors the pupils' level of proficiency and gives an opportunity to apply the knowledge in the context of playing with the past period, improving the mental representation of history.

The next type of game to consider is a role-playing game. Role-playing game is a form of educational activity arranged by the teacher with the aim to attain training goals, during which each student has their own role in the event. History is such a science, where the content cannot be repeated in reality, it is impossible to wish to become participants of events that had happened many years ago. The role-playing game at the history lesson is "implementation of unreal facts and events". Difference of a role-playing game from a regular didactic game lies in more clear structural arrangement, which is presented as a highly structured situation where a participant of the game gets a special role for some time and embodies it in accordance with their views. Such a type of game is aimed at development of the newest behavior models and skills of reflection in the pupils. In most cases, the teacher brings the role-playing game into the educational process when they aspire to provide the pupils with a deeper and more serious understanding of a certain topic, problem, event, so that the children could "feel it through" and develop a clear position of their own. The pupils, participating in the role-playing game will remember their in-game emotions for a long time, and the game itself will stay in the child's memory, thus, holding the knowledge obtained in the game and allowing application of this knowledge outside of the game context. For a teacher, this form of work allows collecting illustrative material for future lessons. The role-playing game, just as many didactic games, performs a number of important functions characteristic of the most general class of game: motivational, educational, recreational function and 
others, but the most important is undoubtedly the training function, and it is this function that defines the value of role-playing game in teacher education. Roleplaying game is a type of game that children love the most. That is why we may omit a question of its often being used at the lessons by teachers. The role-playing game is also good in that it is appropriate for any age group, albeit with certain adjustments and peculiarities. The role-playing game at a history lesson facilitates deeper knowledge of history, extends the spectrum of knowledge sources and interpretation of history. The knowledge obtained becomes personally important, emotionally charged, due to the fact that the pupil had pierced the role of a person from historic past. Such a playing variant of the educational process forms a special attitude, amplifying pupils' cognitive activity. A casual atmosphere of simple communication arises, stimulating pupil's cognition; positions of the teacher and the pupil become equivalent because the teacher is in the role of an observer. Work within a group (collective) facilitates development of mutual assistance style, support, communication, revealing of leadership, obtaining an experience of public speaking. The roleplaying game at the history lessons may bring together well-organized theoretical and practical data, characteristic and emotional, different stages of historical material. During the role-playing game the pupils may imagine something that has never happened in their life, the role-playing game is the most accessible case where the pupils may re-imagine the historical reality. Playing the roles and revealing the pupil's inner self facilitates creative development. The role-playing game helps the pupils easier grasp the historical material which may be harder to understand in a complex text in their textbooks. Understanding the demanding material is much easier for pupils during the playing. Taking roles of participants of the past events, the pupils live through their life, understand the specifics of a distant past and that of characters that they play. Role-playing games at the history lessons model specific situations from the past (or present) where characters from the past function. Creating a special emotional atmosphere is always important when conducting such a lesson dedicated to a certain historical event. When the pupils participate in the game, they involve not only memory, but their communication abilities as well, a creative edge is being formed in a person, interest to knowledge increases, improvisation abilities develop; also, the game helps socialization and prepares for adult life. The game requires the participants to find the necessary information in the sources, distribute and analyze it. Conduction of the game correlates with successfully passing the exams.

Psychological specifics of a concrete period in pupil's development shall be understood, so that the teacher knows which abilities of the pupil may be reliably employed, which are less reliable, and which are better to not engage at all. Otherwise, the effect on the pupils is weaker: both onto their actions and personality. The younger the children, the easier and freer the game, the easier the reason for formation of secrets. Many common and stable children's games may become more complex due to participants growing up. By that they become long-life. In the middle school, the pupils shall be considered adolescents with their own set of problems. Adolescence is usually held as a watershed period in personal development. This period is characterized with such attributes as problems with studies, high fatigue, unstable psyche, all they lead to a new level of mental and intellectual development. The foundation of successful mastery of a school subject, for instance, history, is a cognitive attraction supported by an emotional perception of the environment and attractiveness of the lesson procedure itself. (Emotionality of the gaming process is its significant feature, making it successful and necessary not only among the primary school pupils, but in the middle school as well) [11].

This period is characterized by children forming their individual world and wishing to be adults. Their thoughts and imagination undergo unrestrained development. A number of educational games of various categories is formed unconsciously. The period when the pupils are still in the middle school is a period of an inquisitive mind, willful leaning towards knowledge, a period of pursuits and heavy activity. One needs to consolidate their position in a group, thus, opinion of peers is more important that relationships with a teacher. Adolescence is also characterized by dissociation from what is happening around. The adolescents have a will for everything new, unpredictable, special, something that creates conditions for imagination. In this period, solving the game tasks in collectives is in demand, it is based on joint work in competitions, quizzes; multitasking and fast-paced mode of operation; making a pause is very difficult. The teacher shall create and facilitate the students' wish to discuss, to compete in knowledge and skills, wish to improvise and play a role. The gaming process creates conditions for active development of creative abilities. The main thing in these conditions is interaction on equal terms, without fear, hesitation: impressions appear "then I can as well". That is, the gaming process results in inner liberation. For the teaching method, it is of great importance that gaming technologies have consolidated as a standard approach in teaching through action. An entertaining task is an organic part of the gaming process. At this age, children may faster become friends during the game, they may actively help each other, support each other, catch up, do not seat through the game, then they are not afraid to be renounced, because the team is active and there is always a place for everybody to attain the best results. During the game, the pupil may independently look for the necessary information. A colossal educational work takes place during the game. During the gaming, mastering of knowledge is another one exclusive condition for peer solidarity, a condition for getting interest and recognition of each other, "finding themselves" in passing [11].

In the middle school, didactic games are usually used to conclude consolidation of previously studied material. Most of the didactic games seem to add nothing unknown or new to pupils' knowledge and competences. In reality, they work for the future, because they teach 
schoolchildren to use their knowledge under radically different conditions and set an intellectual task where various cognitive approaches need to be used to find a solution. To understand the process of the game and its condition, it is necessary to listen attentively and grasp the teacher's explanation, concentrate one's attention on the current task, think though various ideas for solution, compare them and generalize. However, as it has been noted above, the didactic game at the lesson is not a goal, but a method of teaching. Middle-school children have already got accustomed to concentrate and think during the game, their attention improves, as does their interest for knowledge [11].

Conducting didactic games in senior high school also has a number of specific features, such as determination for self-realization in society, focus on improving one's speech, providing emotional undertone and humor. At this age, communication during the educational process becomes a fruitful form of interaction between the teacher and the pupils. Interpersonal relationship during the game, directed at solving the set tasks, becomes an efficient way for their solution. Good indicators of the educational process are expressed by the character of motivation, linked to studies. The main motivation that provides high indicators of self-development are interest in knowledge and wish to get new knowledge - they are implemented in the didactic game. During the lessons, high school pupils are characterized by dynamics of thought process, orientation to solution of intellectual tasks, affinity for logical organization and systematization, for independent finding of methods for generalized work with information. During this period, what is more important for the pupil is not mastery of facts, events and detail, but general understanding of the nature and importance of the actions, the pupil is fascinated with interactions between a part and the whole, a concrete action and the general picture of reality. The forms of activity during the educational process where these trends find satisfaction become not only more interesting for a high schooler, but very productive as well. The opposite is also true: the forms limiting pupil's work with mechanical repetition and rote learning meet an intensive internal opposition, which results in them being unproductive.

Thus, didactic game at the history lesson is an independent form of a child-developing activity at any age; it appears as the most spontaneous form of pupil's activity, where they perceive, study and master the environment, develop as a person, activate self-learning, practical development, self-realization, selfunderstanding of the child; the main medium of children's interaction, where experience of their relationships is expressed. Each age group of school children has their own peculiarities in perception and delivery of historical information, thus the games shall be age-appropriate. Finally, the most productive games in high school are business and role-playing games in a historical context.

\section{References}

1. S. A. Yezhova, Methods of Teaching History in Secondary School:A Study Guide for Institutions of Higher Education (Moscow: Prosveschenie, 1986)

2. V.P. Bespalko, Components of Pedagogical Technology (Moscow, 1989)

3. M. I. Osipova, Bulletin of Scientific Conferences 32(19), 87-88 (2017)

4. Federal State Educational Standard [Electronic resource] - Access mode: http://www.edu.ru/db/portal/obschee/index.htm

5. X. Jia, W. Hu, F. Cai, H. Wang, Y. Chen, Thinking Skills and Creativity 24, 86-94 (2017)

6. O. A. Bota, C. Tulbure, Procedia - Social and Behavioral Sciences 203, 285-290 (2015)

7. A. Cunska, I. Savicka, Procedia - Social and Behavioral Sciences 69, 1481-1488 (2012)

8. R. Iglesias, D. Aceituno, M. I. Toledo, Procedia Social and Behavioral Sciences 237, 452-457 (2017)

9. S. A. Levy, The Journal of Social Studies Research 40(1), 5-20 (2016)

10. B. S. Seker, G. G. Sahin, Procedia - Social and Behavioral Sciences 46, 1679-1683 (2012)

11. N. N. Makarova, N. V.Chernova, M. N.Potemkina, A. E. Lyubetsky, I. O. Koldomasov, Man In Indian 97(5), 93-104 (2017) 